\title{
EL ORIGEN DE LA VIDA EN LA TIERRA: ¿ACCIÓN DE LA NATURALEZA Y/O INTERVENCIÓN DIVINA?
}

\author{
Rafael Vicuña*
}

El presente artículo aborda el problema del origen de la vida en la Tierra, sin duda, uno de los más inescrutables desafíos para la ciencia contemporánea. Teniendo en cuenta que la principal dificultad radica en reunir evidencia empírica sobre un acontecimiento irrepetible, como fue el proceso que dio origen a los primeros organismos vivos, trataremos de llegar a una hipótesis de consenso que propicie el encuentro armónico entre filosofía, ciencia y religión.

Palabras clave: vida, naturaleza, evolución, creación, Dios.

\section{THE ORIGIN OF LIFE ON EARTH: ACTION OF NATURE AND/OR DIVINE INTERVENTION?}

The present article addresses the problem of the origin of life on Earth, without a doubt, one of the most inscrutable challenges for contemporary science. Having in mind that the difficulty lies in collecting empirical evidence of an unrepeatable event, such as the process that gave rise to the first living organisms, we will try to reach to a consensus hypothesis conducive to the harmonious meeting between philosophy, science and religion.

Keywords: life, nature, evolution, creation, God.

\footnotetext{
* Pontificia Universidad Católica de Chile, Santiago, Chile. Correo electrónico: rvicuna@bio.puc.cl
} 
El ESTUdio DE LOS ORÍGENES -DEL UNIVERSO, DE LA VIDA, DEL HOMBRE- constituye una instancia privilegiada de encuentro entre la ciencia, la filosofía y la religión. Este ejercicio requiere una clara distinción del plano en que cada una de estas disciplinas hace su particular contribución. Respecto al asunto que se aborda en esta ocasión, es decir, el origen de la vida en la tierra, éste representa sin duda uno de los más inescrutables desafíos para la ciencia contemporánea. La principal dificultad radica en reunir evidencia empírica sobre un acontecimiento que tiene un componente histórico que encierra numerosas incertidumbres y que, a fin de cuentas, resulta irrepetible. Más aún, por mucho que se progrese en las investigaciones, nunca habrá certeza sobre como ocurrió efectivamente en la tierra primitiva el proceso que dio origen a los primeros organismos vivos. Por lo tanto, lo que se espera es alcanzar una hipótesis de consenso apoyada en la mayor cantidad posible de evidencia científica. Esta situación no cambiará aún en el caso de que se logre producir vida en el laboratorio.

Es necesario tener presente que la vida tuvo su origen en un escenario absolutamente distinto al que presenta la tierra actual. Éste se caracterizaba, entre otras cosas, por una radiación solar más suave, una intensa lluvia de meteoritos, una atmósfera desprovista de oxígeno y una luna más cercana que producía bruscos ciclos de mareas. Al estudio de este proceso nos podemos aproximar analizando las rocas más antiguas de la tierra. En ellas se determinan las razones de isótopos de oxígeno y de azufre, así como la presencia y antigüedad de microfósiles. También se pueden hacer algunos ensayos en el laboratorio. Los innovadores experimentos de Stanley Miller iniciados hace justo sesenta años generaron fundadas expectativas para una aproximación experimental a este problema. Hoy sabemos cómo sintetizar la mayoría de las biomoléculas que componen la célula. Esto no quiere decir que la síntesis original ocurrió de la misma manera, pero al menos es un avance. Lo que hasta ahora sigue presentándose como una valla insalvable a la experimentación es el proceso de autoorganización de estas biomoléculas para constituir una entidad viviente.

Las tres cuestiones fundamentales que se suelen plantear cuando se analiza el origen de la vida en la tierra son el cuándo, el dónde y el cómo. Respecto a lo primero, se dispone de datos químicos y de microfósiles bacterianos. Mediciones de la razón ${ }^{13} \mathrm{C} /{ }^{12} \mathrm{C}$ en rocas sedimentarias de $3.700 \mathrm{ma}$. de la isla de Akilia ${ }^{1}$ de la razón ${ }^{34} \mathrm{~S} /{ }^{32} \mathrm{~S}$ en el Isua Belt ${ }^{2}$,

1 Rosing, M., " ${ }^{13}$ C-depleted carbon in $>3,700$-Ma sea-floor sedimentary rocks from West Greenland", Science, 283, 1999, pp. 674-676. 
ambos en Groenlandia, revelan proporciones que sugieren actividad biológica. Lo mismo indica el análisis de dolomita premetamórfica de dichas rocas ${ }^{3}$ y de pirita de $3.400 \mathrm{ma}$ en Sudáfrica ${ }^{4}$. Por otra parte, estromatolitos de Australia muestran evidencias irrefutables de microfósiles de bacterias que metabolizaban sulfuros hace $3.430 \mathrm{ma}^{5}$. Podemos concluir entonces que la vida surgió temprano, apenas las condiciones ambientales lo permitieron, posiblemente antes de que concluyera el bombardeo intenso tardío hace unos $4.000 \mathrm{ma}$. Esta temprana aparición insinúa la existencia de un camino expedito de auto-organización de la materia y permite especular sobre la posibilidad de que la vida se haya iniciado varias veces luego de eventos de esterilización masiva provocados por los cometas que chocaban con el planeta.

Por otra parte, asumiendo que la vida surgió en la tierra y no llegó desde el espacio -lo cual no estamos en condiciones de descartar-, la cuestión sobre el dónde nos remite al escenario más probable. Este es quizás el motivo de mayores disputas entre los especialistas. Los partidarios de la denominada sopa primordial, entre quienes han destacado el propio Miller, Oparin, Haldane y Lazcano, proponen un origen en solución asociado a un metabolismo heterótrofo ${ }^{6}$. Por su parte, aquellos que apoyan un origen en fuentes hidrotermales plantean un inicio sobre una superficie sólida asociado a un metabolismo autótrofo. Los más notables defensores de esta última opción son Günter Wächtershäuser, con su propuesta del mundo hierro azufre o de la pirita presente en las fuentes hidrotermales tipo black smoker y William Martin y Michael Russell para el caso de las fuentes tipo Lost City, de condiciones menos extremas que las anteriores ${ }^{8}$. Ambas teorías cuentan con algún apoyo experimental. Hay también quienes han llegado a proponer un origen en partículas de aerosol o en fuentes hidrotermales terrestres. Por el momento, todas estas opciones respecto del dónde son solo conjeturas.

La pregunta del cómo, sin embargo, es sin duda la más esencial. Una cosa es contar con los elementos materiales y otra muy distinta es lograr que éstos se auto-organicen dando origen a una entidad viva. Una reflexión que hiciera Immanuel Kant a este respecto

2 Grassineau, N.V., Abell, P., Appel, P.W.U., Lowry, D., Nisbet, E.G., "Early life signatures in sulphur and carbon isotopes from Isua, Barberton, Wabigoon (Steep Rock) and Belingwe greenstone belts (3.8 to $2.7 \mathrm{Ga}$ )", en: Kester, S.E.-Онмото, H. (Eds.), Evolution of Early Earth's Atmosphere, Hydrosphere and BiosphereConstraints from Ore Deposits, Boulder, CO: Geol. Soc. Am. Spec. Publ., 2006, pp. 33-52.

3 Nutman, A.P., Friend, C.R.L., Bennet, V.C., Wright, D., Norman, M.D., " $\geq 3700$ Ma pre-metamorphic dolomite formed by microbial mediation in the Isua supracrustal belt (W. Greenland): Simple evidence for early life?", Precambrian Research 183, 2010, pp. 725-737.

4 Онмото, H., KaKegawa, T., Lowe, D.R., "3.4-bilion-year-old biogenic pyrites from Barbeston, South Africa: Sulphur isotope evidence", Science, 262, 1993, pp. 555-557.

5 Allwood, A.C., Grotzinger, J.P., Knoll, A.H., Burch, I.W., Anderson, M.S., Coleman, M.L., Kanik, I., "Controls on development and diversity of early Archean stromatolite", Proc. Natl. Acad. Sci. USA 106, 2009, pp. 9548-9555.

6 Lazcano, A., Miller, S.L, "The origin and early evolution of life: Prebiotic chemistry, the pre-RNA world and time", Cell 85, 1996, pp. 793-798.

7 Wächtershäuser, G., "From volcanic origins of chemoautotrophic life to Bacteria, Archea and Eukarya", Phil. Trans. Royal Soc. B 361, 2006, pp. 1787-1808.

8 Martin, W., Russell, M.J., "On the origin of biochemistry at an alkaline hydrothermal vent", Phil. Trans. Royal Soc. B 362, 2007, pp. 1887-1925. 
resulta particularmente ilustrativa: "Porque, que la materia bruta se haya originariamente formado por sí misma según leyes mecánicas, que la vida haya podido salir de la naturaleza muerta, y que la materia haya podido tomar espontáneamente la forma de una finalidad que se conserve por sí misma, es lo que se mira justamente como absurdo"9.

Una manera de aproximarse a esta cuestión es pensar en mecanismos de auto-organización. Existe uno de tipo espontáneo que encontramos en situaciones tales como el plegamiento de las proteínas, la formación de vesículas y micelas y el ensamblaje de virus y ribosomas. Todas estas son estructuras moleculares que pueden maravillar por su funcionalidad e incluso por su valor estético, pero son solo eso, es decir, estructuras. Por otra parte, están las estructuras disipativas descritas por Ilya Prigogine ${ }^{10}$, en las que se alcanza un orden transitorio en la medida que se provea al sistema de algún tipo de energía. Los típicos ejemplos que se citan una y otra vez son las células de Bénard y los tornados, sistemas bastante más simples que una célula. Difieren además de la vida en un elemento fundamental: no son autónomas en la mantención de su estado de estructura disipativa. Existen además modelos teóricos de auto-organización, como las redes metabólicas de Stuart Kauffman ${ }^{11}$ y los hiperciclos de Manfred Eigen ${ }^{12}$. De un indudable valor creativo, ambos modelos pueden ser simulados en computadores, pero no han logrado ser reproducidos en el laboratorio.

Un aspecto que dificulta enormemente concebir el "cómo" es la extraordinaria complejidad de la vida. Se puede teorizar que el organismo más simple podría consistir en un polímero informativo que se autocopia y que copia, además, a otro polímero involucrado en la síntesis de los lípidos de la membrana que confina al sistema autopoiético ${ }^{13}$. Por cierto, esto sería posible si los precursores de ambos polímeros se sintetizaran abióticamente usando alguna fuente de energía disponible. Sin embargo, las células existentes distan mucho de parecerse a esta hipotética entidad. La bacteria Mycoplasma genitalium es de las más simples que se conocen y no se ha logrado reducir su genoma a menos de 425 genes $^{14}$. Sabemos también que estas proteínas interaccionan entre ellas y con el genoma a través de múltiples redes y que éstas disponen de mecanismos de control por retroalimentación que le permiten a la célula reaccionar frente a los estímulos del medio. Por otra parte, se ha calculado que cada célula de Escherichia coli contiene en su interior unos 100 millones de moléculas de metabolitos y 2.4 millones de moléculas de proteína ${ }^{15}$. Parece ser, entonces, que la vida como la conocemos requiere de un umbral mínimo de complejidad.

9 KAnt, I., Crítica del Juicio, \$80, ed. 1790.

10 Prigogine, I., Order out of chaos: Man's new dialogue with Nature, Bantam Books, Toronto, 1984.

11 Kauffman, S.A., The origins of order: Self-organization and selection in evolution, Oxford University Press, New York, 1996.

12 EIgen, M., Steps towards life. A perspective on evolution, Oxford University Press, Oxford, 1992.

13 Szostak, J.W., Bartel, D.P., Luisi, P.L., "Synthesizing life", Nature 409, 2001, pp. 387-390.

14 Glass, J.I., Assad-García, N., Alperovich, N., Yooseph, S., Lewis, M.R., Maruf, M., Hutchinson, C.A., Smith, H.O, Venter, J.C., "Essential genes of a minimal bacterium”, Proc. Natl. Acad. Sci. USA 103, 2006, pp. 425-430.

15 Bennett, B.D., Kimball, E.H., Gao, M., Osterhout, R., Van Dien, S.J., Rabinowitz, J.D., "Absolute metabolite concentrations and implied enzyme active site occupancy", Escherichia coli. Nat. Chem. Biol.5, 2009, pp. 593-599. 
La dualidad metabolismo-genética contribuye decisivamente a esta complejidad. Es posible que inicialmente hayan aparecido macromoléculas informacionales como el RNA u otras semejantes, aunque su autocopia parece particularmente problemática. Es también posible que la vida haya comenzado antes con un metabolismo rudimentario. Cualquiera fuese el caso: ¿consideraríamos que posee vida un RNA capaz de hacer copias de sí mismo? O bien, ¿podríamos decir que un sistema de reacciones químicas sustentado en alguna fuente de energía externa y carente de polímeros informacionales está vivo, aunque crezca y evolucione hacia otros sistemas más elaborados? En todo caso, aunque en sus inicios la vida haya tenido una menor complejidad, es difícil creer que ésta haya surgido súbitamente por azar. Parece más lógico pensar que una vez dadas ciertas condiciones ambientales, ello haya ocurrido a través de una serie de etapas sucesivas, todas ellas cumpliendo las leyes de la físico-química. Claro que este camino, que parece muy razonable, nos enfrenta a otra dificultad no menor: una transición paulatina de lo inerte a lo vivo implica el paso por situaciones intermedias que nos obligarían a precisar el momento en que nos encontramos en presencia de vida, ya que no podemos concebir que existan entidades medio inertes o medio vivas.

Estas preguntas nos llevan de lleno al concepto de vida. Hay quienes afirman que la vida es solo materia organizada de una forma particular a partir de moléculas complejas. Me imagino que quienes así piensan estiman que la biología constituye una de las ramas de la física. Lord Rutherford decía que existe solo una ciencia, la física, y que todo lo demás equivale a coleccionar estampillas ${ }^{16}$. Pero si la vida consistiera solo en materia organizada la podríamos explicar a partir de sus componentes, lo que hasta ahora no ha sido posible. Sabemos que la vida obedece las leyes de la físico-química, aunque no es explicable únicamente a partir de ellas. No ocurre lo mismo con las máquinas, que por complicadas que sean, no son más que la previsible suma de sus partes. Pensar que la vida es algo más que sus constituyentes moleculares no implica ser partidario de un vitalismo como el propuesto por Bergson. Sin embargo, cualidades de la vida como la autoorganización, la mantención autónoma del desequilibrio termodinámico, la dualidad metabolismo-genética y la evolución darwiniana, entre otras, parecen indicarnos que los seres animados poseen una categoría ontológica superior al que tiene el conjunto de sus componentes materiales.

Esta dificultad de reducir todos los aspectos de la vida solo a causas mecánicas ha sido manifestada por innumerables pensadores, entre los que se encuentran Immanuel Kant (“es absurdo esperar que un nuevo Newton vendrá un día a explicar la producción de un tallo de yerba por leyes naturales"17), Niels Bohr ("hay una imposibilidad de una explicación física o química de las funciones peculiares a la vida"18) y Erwin Chargaff ("la vida

16 BiRKs, J.B., Rutherford at Manchester, Heywood, London, 1962.

17 Kant, I., Critique of Judgement, ed. 1790.

18 Bohr, N., "Light and life", Nature 133, 1933, pp. 421-423, pp. 457-459. 
es la continua intervención de lo inexplicable"19). En sus conferencias sobre Qué es la vida, casi al promediar el siglo pasado, Erwin Schrödinger hizo una invitación a descubrir nuevas leyes de las ciencias naturales que permitieran dar respuesta a esta interrogante ${ }^{20}$. El también premio Nobel Max Delbrück fue aún más audaz, al sostener que el análisis de los seres vivos debía acometerse sin temor de contradecir las leyes de la física molecular ${ }^{21}$. Pero estas nuevas leyes nunca se descubrieron y nos hemos quedado con la constatación de que, si bien la vida obedece las leyes de la físico-química, no es explicable solo a partir de ellas.

Quienes sostienen una postura reduccionista frente a la vida suelen también agregar que no ha sido necesaria la acción de un creador. El ya citado científico norteamericano Stuart Kauffman, muy conocido por sus estudios sobre complejidad y auto-organización, nos ofrece un claro ejemplo de esta posición: "Al devoto que requiere un Dios Creador de la vida, la ciencia le dice: espera, estamos comenzando a entender cómo ésta apareció naturalmente sin la participación de un Creador....la vida es una expresión emergente natural de la creatividad rutinaria del universo" 22 . La verdad es que cuesta entender esta lógica, porque la ciencia positiva no permite confirmar ni descartar la existencia de Dios. O puesto de otro modo, ¿qué cualidades debiera tener la vida para que la participación de un creador resulte ineludible? ¿Podría ser en el caso, por ejemplo, que la vida violara las leyes de la físico-química y que por lo tanto nos pareciera milagrosa?

Un error epistemológico comparable al anterior lo encontramos al invocarse la participación de un creador cuando no se comprende un proceso natural. Esta es la clásica doctrina del Dios tapa agujeros, la que paradojalmente conduce a un arrinconamiento de Dios a medida que se progresa en el conocimiento científico. En este error han incurrido notables hombres de ciencia, entre los que se cuenta a Isaac Newton. En nuestros días, su mejor exponente es la doctrina del Diseño Inteligente ${ }^{23}$, cuyos partidarios creen en el proceso evolutivo, aunque sostienen que ciertas estructuras moleculares que les aparecen de complejidad irreductible han requerido la intervención directa de un creador en el orden natural. Con esta postura ellos no solo están negando la autonomía de la naturaleza, sino que revelan desconocimiento de la evidencia científica que ha demostrado claramente que las estructuras irreductiblemente complejas han aparecido por evolución darwiniana.

A la convicción de la existencia en un Dios creador del universo y de la vida se puede llegar solo después de una adecuada reflexión filosófica, realizada con una actitud interior abierta y libre de prejuicios. Viene al caso recordar las frecuentes menciones del Papa emérito Benedicto XVI sobre la necesidad de acompañar el desarrollo de la ciencia con un

19 Chargaff, E., In Heraclitan fire: Sketches from a life before Nature, Seabury, New York, 1977.

20 Schrödinger, E., What is life?, Cambridge University Press, Cambridge, 1967.

21 Delbrück, M.A., "Physicist looks at biology", Trans. Connect. Acad. Arts Sci., 38, 1949, pp. 173-190.

22 Kauffman, S.A., Reinventing the sacred. A new view of science, reason and religion, Basic Books, New York, 2008, pp. 59-89.

23 Behe, M.J., Dembski, W., Meyer, S., Science and evidence for design in the universe, Ignatius Press, San Francisco, 2002. 
raciocinio filosófico crítico abierto a dimensiones de las cuales la ciencia solo puede mostrar aspectos particulares ${ }^{24}$. En su célebre discurso en la Universidad de Ratisbona, el año 2006, fue particularmente explícito en su invitación a que ampliemos nuestra racionalidad para que ésta pueda alcanzar su plena capacidad de comprensión y de verdad, yendo más allá de lo que puede demostrar la experimentación.

En el tema que comentamos, este ejercicio nos remite ineludiblemente al argumento del diseño, llamado también argumento físico-teológico o teleológico. Este no debe ser confundido con la doctrina del Diseño Inteligente recientemente mencionada, la cual confunde equivocadamente el plano científico con el filosófico. El argumento físico-teológico se sustenta en el aparente diseño, orden y propósito que se observa en la naturaleza. Quizás la primera mención a dioses responsables del movimiento de los astros y del "bello orden" natural fue hecho por Platón ${ }^{25}$. Algo semejante plantearon más tarde Cicerón ${ }^{26}$ y San Agustín ${ }^{27}$. Una variante de este argumento lo emplearía Santo Tomás en su quinta vía de prueba de la existencia de Dios ${ }^{28}$. Más tarde Francis Bacon le daría una nueva forma a este argumento al decir que los dos libros mediante los cuales nos habla Dios son la Biblia y el libro de las creaturas. A comienzos del siglo XIX, el clérigo inglés William Paley publica su libro Teología Natural, o evidencias de la existencia y de los atributos de la Deidad. En esta obra, una de las más citadas en discusiones posteriores sobre el tema, Paley sigue la huella dejada por el naturalista inglés John Ray ${ }^{29}$. Paley se maravilla con la extraordinaria organización de los seres vivos y de los procesos biológicos. Tal complejidad y perfección, sostiene él, no pueden deberse al azar, sino que reflejan un diseño. Puesto que no puede haber diseño sin diseñador o invento sin inventor, ellos constituyen prueba de la existencia de un Dios creador con inteligencia. Podemos afirmar que al razonar de este modo, los partidarios del argumento del diseño están haciendo eco de expresiones de la Sagrada Escritura tales como: "A partir de la grandeza y hermosura de las criaturas se llega, por analogía, a contemplar a su autor" (Sabiduría 13, 5), o "Lo invisible de Dios, desde la creación del mundo, se deja ver a la inteligencia a través de sus obras" (Romanos 1, 20).

24 Ratzinger, J., "That which holds the world together: the pre-political moral foundations of a free state", en Habermas, J. - Ratzinger, J., The dialectics of secularization. On reason and religion, Florian Schuller, Ignatius Press, San Francisco, 2006.

25 Platón, Leyes, Libro X.

26 "Pero puede haber una persona.....que pueda considerar el movimiento regular de los cuerpos celestes, las trayectorias de las estrellas, y ver como todo está unido en un solo sistema, y luego negar que hay un propósito consciente y afirmar que es solo un resultado del azar?" (...) "Qué podría ser más claro y obvio cuando contemplamos el cielo que existe una divinidad o inteligencia superior?". CicERón, Sobre la naturaleza de los dioses (De Natura Deorum.), $45 \mathrm{BC}$.

27 "Interroga a la belleza de la tierra, interroga a la belleza del mar, interroga a la belleza del cielo... interroga a todas estas realidades. Todas te responden: 'Somos bellas'... Pues bien, estas bellezas sujetas a cambio, ¿quién las ha hecho sino la Suma Belleza que no está sujeta a cambio?”. St. Augustine, Sermo 241, 2.

28 "Los seres que carecen de consciencia muy frecuentemente obran de la misma manera para conseguir lo mejor Luego, existe un ser inteligente por el cual todas las cosas naturales se ordenan al fin: a este ser lo llamamos Dios". Sт. Thomas Aquinas, Summa Theologica, a. 3, q. 2.

29 "The Almighty discovers more of his Wisdom in forming such a vast multitude of different sorts of creatures, and all with admirable and irreprovable Art, than if he had created but a few; for this declares the greatness and unbounded capacity of his Understanding". RAY, John, The Wisdom of God Manifested in the Works of the Creation, London, 1691. 
El argumento del diseño no ha estado carente de críticas, destacando entre ellas las de David Hume ${ }^{30}$ e Immanuel Kant ${ }^{31}$. En particular, y más recientemente, Paley ha recibido críticas del evolucionista español Francisco Ayala y del filósofo chileno Roberto Torretti. Según el primero, el gran legado de Darwin a la ciencia y a la religión fue resolver la esquizofrenia intelectual propia del argumento del diseño demostrando que efectivamente hay un diseño, pero que éste no obedece a un diseñador sobrenatural, sino a un proceso natural carente de consciencia ${ }^{32}$. Una tesis parecida desarrolla Torretti, aunque este autor admite que un científico puede creer en un Dios personal autor de las leyes con que opera la naturaleza, pero que se debe admitir que la ciencia en nada contribuye a dar sustento a esta creencia ${ }^{33}$.

Es muy legítimo discrepar de Paley en el plano filosófico, pero no se puede decir que Darwin comprobó que el argumento teleológico es errado, puesto que éste último no se inmiscuye en los procesos o mecanismos naturales conducentes al aparente diseño. Por este mismo motivo, tampoco se puede decir que el argumento del diseño contradice a Darwin. Hasta el propio Darwin fue presa del vértigo de descartar la existencia de un creador a partir de sus observaciones científicas, al admitir en su autobiografía que si bien de joven se había visto impelido a buscar una Causa Primera poseedora de una mente inteligente, más tarde descubriría que el viejo argumento del diseño presentado por Paley, que antes le parecía tan concluyente, falla ahora que la ley de la selección natural ha sido descubierta.

Pues bien, si nuestra reflexión nos condujera al convencimiento de que existe un Dios creador, ¿cómo podríamos armonizar su acción con la autonomía de los procesos naturales? Santo Tomás de Aquino ha propuesto un camino de pensamiento al respecto. Para este filósofo, la dependencia radical que todas las cosas creadas tienen de Dios es totalmente compatible con la causalidad de los eventos naturales, puesto que la causalidad divina y la causalidad en la naturaleza operan a distintos niveles. Dios causa de tal modo la existencia de las cosas, que ellas son las causantes de sus propias operaciones. Un mismo acontecimiento no tiene una causa natural y una divina, respondiendo en parte a cada una de ellas. Más bien, responde totalmente a ambas, cada una actuando a su modo. Dios trasciende de tal modo a la naturaleza, que Él es causa de que incluso los eventos del azar sean tales, es decir, eventos de azar, del mismo modo que Él es causa de que los actos libres de los seres

30 En su obra Diálogos concernientes a la religión natural (1779), Hume sostiene que los artefactos hechos por el hombre difieren sustancialmente de las cosas de la naturaleza, de modo que no se pueden hacer inferencias sobre el diseño de estas últimas. Además, la fracción del universo que vemos los humanos es muy pequeña y bien podría haber caos en otras partes de él.

31 Kant no solo criticó el argumento teleológico, sino también los argumentos ontológico y cosmológico. En su Crítica de la razón pura (1781) afirma que el argumento del diseño no resulta concluyente para inferir de él la existencia de un creador sobrenatural, porque nuestra percepción solo puede asignar causalidades en el mundo sensible. Más tarde, en su Crítica del Juicio (1790) agregaría que colocar sobre por la naturaleza a un ser inteligente que fuese su artífice resulta temerario.

32 Ayala, F.J., "Darwin's greatest discovery: Design without a designer", Proc. Natl. Acad. Sci. USA 104, 2007, pp. 8567-8573.

33 Torretti, R., “Diseños y designios”, Estudios Públicos, 115, 2009, pp. 49-74. 
humanos sean actos libres ${ }^{34}$. La Comisión Católica Internacional Teológica ha recogido esta doctrina tomista afirmando que "la causalidad divina y la causalidad de las criaturas difieren radicalmente en su modo....Así, un acontecimiento natural verdaderamente contingente puede sin embargo ser parte del plan providencial de Dios para la creación" 35 .

Quienes creemos en un Dios creador del universo y de la vida pensamos que Él actúa de ordinario en el mundo en concordancia con las leyes naturales. Esta creencia, que responde a un razonamiento personal que trasciende a la ciencia ofrece un sentido al orden que se observa en la naturaleza y se aviene con lo que expresa el Salmo 104, 29-30: "Les quitas el hálito, dejan de ser y vuelven al polvo. Envías tu Espíritu, son creados y renuevas la faz de la tierra"**

\section{Bibliografía}

Allwood, A.C., Grotzinger, J.P., Knoll, A.H., Burch, I.W., Anderson, M.S., Coleman, M.L., KANIK, I., "Controls on development and diversity of early Archean stromatolite", Proc. Natl. Acad. Sci. USA 106, 2009, pp. 9548-9555.

Augustine, St., Sermo.

Ayala, F.J., "Darwin's greatest discovery: Design without a designer”, Proc. Natl. Acad. Sci. USA 104, 2007, pp. 8567-8573.

Behe, M.J., Dembski, W., Meyer, S., Science and evidence for design in the universe, Ignatius Press, San Francisco, 2002.

Bennett, B.D., Kimball, E.H., Gao, M., Osterhout, R., Van Dien, S.J., Rabinowitz, J.D., "Absolute metabolite concentrations and implied enzyme active site occupancy", Escherichia coli. Nat. Chem. Biol.5, 2009, pp. 593-599.

Birks, J.B., Rutherford at Manchester, Heywood, London, 1962.

Bohr, N., "Light and life”, Nature 133, 1933, pp. 421-423; pp. 457-459.

Chargaff, E., In Heraclitan fire: Sketches from a life before Nature, Seabury, New York, 1977.

34 Thomas Aquinas, St., Summa against the Gentiles, Book 1, Chapter 85; Book 3, Chapters 70-77.

35 International Theological Commission, Communion and stewardship, $\mathrm{N}^{\circ}$ 69, 2004.

*Artículo recibido: 12 de noviembre de 2014. Aceptado: 19 de diciembre de 2014. 
Cíerón, Sobre la naturaleza de los dioses.

Delbrück, M.A., "Physicist looks at biology", Trans. Connect. Acad. Arts Sci., 38, 1949, pp. 173-190.

EIGEn, M., Steps towards life. A perspective on evolution, Oxford University Press, Oxford, 1992.

Glass, J.I., Assad-García, N., Alperovich, N., Yooseph, S., Lewis, M.R., Maruf, M., HutChinson, C.A., Smith, H.O, Venter, J.C., "Essential genes of a minimal bacterium", Proc. Natl. Acad. Sci. USA 103, 2006, pp. 425-430.

Grassineau, N.V., Abell, P., Appel, P.W.U., Lowry, D., Nisbet, E.G., "Early life signatures in sulphur and carbon isotopes from Isua, Barberton, Wabigoon (Steep Rock) and Belingwe greenstone belts (3.8 to $2.7 \mathrm{Ga}$ )", en: KesLer, S.E.-Оhмото, H. (Eds.), Evolution of Early Earth's Atmosphere, Hydrosphere and Biosphere-Constraints from Ore Deposits, Boulder, CO: Geol. Soc. Am. Spec. Publ., 2006, pp. 33-52.

International Theological Commission, Communion and stewardship, № 69, 2004.

Kant, I., Crítica del Juicio, §80, ed. 1790.

Kauffman, S.A., The origins of order: Self-organization and selection in evolution, Oxford University Press, New York, 1996.

, Reinventing the sacred. A new view of science, reason and religion, Basic Books, New York, 2008, pp. 59-89.

Lazcano, A., Miller, S.L, "The origin and early evolution of life: Prebiotic chemistry, the pre-RNA world and time", Cell 85, 1996, pp. 793-798.

Martin, W., Russell, M.J., "On the origin of biochemistry at an alkaline hydrothermal vent”, Phil. Trans. Royal Soc. B 362, 2007, pp. 1887-1925.

Nutman, A.P., Friend, C.R.L., Bennet, V.C., Wright, D., Norman, M.D., “ $\geq 3700$ Ma pre-metamorphic dolomite formed by microbial mediation in the Isua supracrustal belt (W. Greenland): Simple evidence for early life?", Precambrian Research 183, 2010, pp. 725-737.

Онмото, H., KaKegawa, T., Lowe, D.R., "3.4-bilion-year-old biogenic pyrites from Barbeston, South Africa: Sulphur isotope evidence”, Science, 262, 1993, pp. 555-557.

Platón, Leyes. 
Prigogine, I., Order out of chaos: Man's new dialogue with Nature, Bantam Books, Toronto, 1984.

RATZINGER, J., "That which holds the world together: the pre-political moral foundations of a free state", en Habermas, J. y Ratzinger, J., The dialectics of secularization. On reason and religion, Florian Schuller, Ignatius Press, San Francisco, 2006.

RAY, J., The Wisdom of God Manifested in the Works of the Creation, London, 1691.

Rosing, M., " 13 C-depleted carbon in $>3,700$-Ma sea-floor sedimentary rocks from West Greenland", Science, 283, 1999, pp. 674-676.

SchröDinger, E., What is life?, Cambridge University Press, Cambridge, 1967.

Szostak, J.W., Bartel, D.P., Luisi, P.L., “Synthesizing life”, Nature 409, 2001, pp. 387-390.

Thomas Aquinas, St., Summa Theologica.

, Summa against the Gentiles.

Torretti, R., “Diseños y designios”, Estudios Públicos, 115, 2009, pp. 49-74.

WÄCHTERSHÄUSER, G., "From volcanic origins of chemoautotrophic life to Bacteria, Archea and Eukarya”, Phil. Trans. Royal Soc. B 361, 2006, pp. 1787-1808. 